\title{
Evaluación en casa malla del efecto de cuatro productos biológicos para el combate de jobotos (Phyllophaga sp.)
}

Evaluation in house mesh of the effect of four biological products for the combat of jobotos (Phyllophaga sp.)

Ricardo Acuña-Segura ${ }^{1}$, Jaime Brenes-Madriz²

Fecha de recepción: 11 de setiembre de 2019

Fecha de aprobación: 4 de diciembre de 2020

Acuña-Segura, R; Brenes-Madriz, J. Evaluación en casa malla del efecto de cuatro productos biológicos para el combate de jobotos (Phyllophaga sp.). Tecnología en Marcha. Vol. 33-4. Octubre-Diciembre 2020. Pág 140-154.

doi) https://doi.org/10.18845/tm.v33i4.4376

1 Bio - Control. Costa Rica. Correo electrónico: racuna@biocontrol.cr

2 Ingeniero agrónomo. Escuela de Biología, Centro de Investigaciones en Biotecnología. Instituto Tecnológico de Costa Rica. Costa Rica. 


\title{
Palabras clave
}

Control biológico; Beauveria sp.; Bacillus spp.; entomonemátodo; Phyllophaga sp.

\begin{abstract}
Resumen
El experimento se desarrolló en casa malla y se evaluó el efecto y las dosis de cuatro productos biológicos y uno químico utilizados en el control de larvas de jobotos (Phyllophaga sp.). El experimento se desarrolló en Guadalupe de Cartago. Fue una investigación cuantitativa con un diseño de experimento de bloques completos al azar, con el uso de dos dosis de cinco tratamientos, con tres repeticiones cada uno y cada repetición con diez unidades experimentales. Los productos biológicos utilizados fueron Mycotrol@ $11 \mathrm{EW}$ (Beauveria bassiana, cepa GHA), Botani Gard® 50 WP (Beauveria bassiana, cepa GHA), Agro Gold® (nueve cepas de Bacillus spp.), B-Green ${ }^{\circledR}$ (entomonemátodo, Heterorhabditis bacteriophora) y un producto químico comercial recomendado para control de jobotos. Se determinó que Mycotrol ${ }^{\circledR} 11 \mathrm{EW}(\mathrm{T} 1)$ en dosis de 2,25 centímetros cúbicos por litro de agua fue el producto que proporcionó los mejores resultados. De los otros dos productos que tuvieron efecto sobre el combate de esta plaga, el Agro Gold® (T3) y el B- Green® (T4), se determinó que la dosis utilizada en ambos casos no fue significativa, ya que se obtuvo valores de $p$ iguales a 0,113 y 0,807 , respectivamente. Lo que sí tuvo significancia fue realizar dos aplicaciones con frecuencia semanal con estos dos productos. Con los productos restantes, Botani Gard® 50 WP (T2) (Beauveria bassiana, cepa GHA) y T5 (producto químico comercial), no hubo resultados de significancia estadística, ya que el valor de $p$ para T2 con el factor dosis fue de 0,573 y con el factor aplicación fue 0,094; para T5 el valor de $p$ con el factor dosis fue 0,260 y con el factor aplicación fue 0,277.
\end{abstract}

\section{Keyword}

Biological control; Beauveria sp.; Bacillus spp.; entomonematode; Phyllophaga sp.

\section{Abstract}

The experiment was developed at home mesh in order to evaluate the effect and dose of four biological products and one chemical used in the control of larvae of jobotos (Phyllophaga sp.). The experiment was carried out in Guadalupe, Cartago, located at the following geographic coordinates: latitude 9,861 884 and longitude -83,939 692, at 1400 m.a.s.I. The type of research was quantitative, with a design of the complete block experiment at random, and use of two doses of five treatments and three repetitions of each treatment, and each repetition with ten experimental units. The biological products used were Mycotrol ${ }^{\circledR} 11 \mathrm{EW}$ (Beauveria bassiana, strain GHA), Botani Gard® 50 WP (Beauveria bassiana, strain GHA), Agro Gold® (nine strains of Bacillus spp.), B-Green® (entomonematode, Heterorhabditis bacteriophora), and a commercial chemical recommended for control of jobotos. For the biological control of Phyllophaga sp., it was determined that Mycotrol ${ }^{8} 11 \mathrm{EW}$, in a dose of 2,25 cc/liter of water, was the product that provided the best results. For the other two products that had an effect on the combat of Phyllophaga sp., Agro Gold $\otimes$ and B-Green $\Theta$, it was determined that the dose used in both cases was not significant; this was confirmed by the $p$ values of 0,113 and 0,807 , respectively. What did have significance was to make two applications one week apart from each other with these two products. For the remaining products, $\mathrm{T} 2$ and $\mathrm{T} 5$, there was no statistical significance in their result. This was confirmed by the $p$ value for T2 and T5, respectively,. For T2 it was 0,573 for the dose factor and 0,094 for the application factor. For T5 the value of $\mathrm{p}$ for the dose factor was 0,260 and for the application factor, 0,277. 


\section{Introducción}

Ante la necesidad de nuevas opciones de manejo y control de plagas, el ser humano ha enfocado su conocimiento en la búsqueda de soluciones que cumplan con los requerimientos necesarios para hacer frente a los problemas que las plagas ocasionan en los cultivos. Tradicionalmente se han utilizado los productos agroquímicos, pero el uso indiscriminado de plaguicidas ha generado su resistencia a las moléculas de uso común, además de causar daño al agricultor, al consumidor y al ambiente [1].

Una de las opciones es el Manejo Integrado de Plagas y Enfermedades (MIPE), que busca un resultado más sostenible de la actividad agrícola que se realiza, abarcando áreas de trabajo como prácticas culturales (propias de manejo del cultivo), manejo químico (con productos de bajo impacto para las personas y para el ambiente), la etológica (utilización de trampas, feromonas), la botánica (extractos de plantas o sus derivados) y la biológico (utilización de hongos entomopatógenos, bacterias, virus, artrópodos).

El género Phyllophaga, conocido como joboto, se ha convertido en los últimos años en una de las plagas insectiles más problemática para los agricultores, debido a que facilita el ingreso de enfermedades, ya que al afectar el sistema radicular permite la entrada de hongos y bacterias fitopatógenas que se aprovechan de las heridas dejadas por las larvas al alimentarse.

Este género está asociado a daños de gran magnitud a nivel de raíces en los cultivos, pudiendo llegar a ser devastador. No tiene límite de cultivo y ataca desde pastos, hortalizas y especies forestales hasta ornamentales. El daño ocasionado en las raíces abarca todo el sistema radicular, llegando a provocar en condiciones extremas la muerte del cultivo. El combate se debe enfocar preventivamente, ya que a menor tamaño de las larvas es más probable tener más éxito con la estrategia utilizada [2].

En Costa Rica se realizó un estudio con la finalidad de identificar las especies de Phyllophaga $s p$. presentes en algunas zonas agrícolas y determinar su asociación con diferentes cultivos; se logró determinar que las especies del género Phyllophaga predominantes son $P$. menetriesi, $P$. obsoleta, P. zunilensis, P. elenans, P. vicina y P. valeriana [3].

Phyllophaga sp. es un insecto de metamorfosis completa; su desarrollo tiene cuatro etapas: huevo, larva, pupa y adulto. Si bien el adulto es capaz de alimentarse del follaje de muchos cultivos, es en la etapa de larva cuando más problema presenta por sus hábitos rizófagos. Sus especies pueden completar el ciclo viviendo en el suelo hasta por dos años. En su ciclo biológico tiene tres estadíos en forma de larva; el tercero es el que puede causar más daño [4]. Su clasificación taxonómica se define así: clase: Insecta, orden: Coleoptera, familia: Scarabaeidae, subfamilia: Melolonthinae y género: Phyllophaga, especie: (spp.) (5).

El manejo cultural de esta plaga es importante.; por ejemplo, al mecanizar el suelo, las larvas quedan expuestas al sol y se desecan o son comidas por las aves. Otra estrategia es la captura de adultos machos y hembras utilizando trampas de luz. Sumado a esta lista de opciones para el manejo y control de Phyllophaga sp., se considera el control biológico como una opción que se describe como el uso de microorganismos benéficos con acción nociva contra las larvas de este insecto. Con su empleo se intenta restablecer el perturbado equilibrio ecológico, mediante la utilización de organismos vivos o sus metabolitos, para eliminar o reducir los daños causados por organismos perjudiciales como los jobotos [6].

Para su control y combate tradicionalmente se han usado insecticidas químicos, los cuales deben ser elegidos bajo un concepto de uso racional y sobre todo, efectivo. El precio de estos productos es alto y cada vez son menos menos eficientes, ya que esta plaga ha adquirido resistencia a las moléculas más comunes que existen en el mercado, como por ejemplo las pertenecientes a los grupos piretroides, organofosforados, benzoylurea y neonicotinoides [7]. 
Aún con el uso de estos agroquímicos las poblaciones de esta plaga siguen incrementándose y para complicar más la situación, estos productos utilizados son muy tóxicos y de difícil degradación, ocasionando problemas de contaminación.

Actualmente la agricultura se está desarrollando con una tendencia hacia la disminución en el uso de productos químicos, especialmente de las moléculas más tóxicas y perjudiciales para todos los involucrados en el proceso productivo. El manejo y combate de plagas y enfermedades está tomando una orientación más amigable con el ambiente, procurando la sostenibilidad de la actividad agrícola.

El control biológico toma un papel relevante dentro de las estrategias MIPE, mediante la utilización de productos derivados de organismos vivos [6] y tiene una aplicabilidad muy amplia en la producción agrícola, ya que no solo se limita al combate de plagas, sino que también se utiliza para combatir hongos, bacterias y nemátodos.

Entre los productos microbiológicos destacan los hongos y bacterias entomopatógenos, siendo los hongos los que más impacto tienen en el proceso de combate de plagas, ya que las condiciones ambientales pueden favorecer o disminuir su acción. Entre las clases de hongos entomopatógenos, tenemos los Hyphomycetes, que incluye al a Beauveria bassiana, que se utiliza para el control de esta plaga [6].

El mecanismo que aplican los hongos entomopatógenos sobre los insectos plaga consta de varias etapas: la adhesión o fijación sobre el insecto blanco es la primera; posteriormente el biocontrolador produce estructuras capaces de penetrar el insecto y germina para así ingresar al hospedero. Una vez que ha penetrado y llega a su hemocele, viene la etapa de infección, en la que produce las toxinas que causan la muerte del insecto hospedero [8].

Los microorganismos entomopatógenos usados en el control biológicocincluyen los virus, bacterias, hongos, protozoos y nematodos. La comparación entre estos organismos y los insecticidas químicos convencionales se suele hacer en base a la eficacia y el costo [9].

Las bacterias también forman parte de las herramientas microbiológicas y son utilizadas con mucha frecuencia en los programas MIPE. En este grupo, Bacillus thuringiensis. B. sphericus y $B$. popilliae presentan un rango de acción amplio para el combate de plagas y pueden atacar órdenes de insectos como Díptera, Ortóptera, Hymenóptera y Coleóptera [3].

Otro grupo importante de microorganismos muy utilizados en la agricultura para combatir plagas son los nemátodos entomopatógenos. Dentro del control biológico sobre larvas de escarabajo, se han evaluado diferentes especies de las familias Steinernematidae y Heterorhabditidae. Estas se caracterizan por estar asociadas a bacterias simbiontes que matan rápidamente al insecto parasitado [10].

Esta investigación tuvo como objetivo general evaluar el efecto y las dosis de cuatro productos biológicos utilizados en el control biológico de larvas de jobotos (Phyllophaga sp.) en ambientes protegidos.

\section{Metodología}

El experimento se desarrolló en Guadalupe de Cartago, en las coordenadas geográficas latitud: 9,861 884 y longitud: 83,939 692, a 1400 m.s.n.m. Se utilizó una casa malla (ambiente controlado), con malla antiafidos (Mesh 50 x 25). Una casa malla consiste en una estructura fabricada para proteger contra radiaciones solares y altas temperaturas los cultivos que allí se desarrollen, que consta de una estructura de soporte metálica cubierta por todos sus lados con una malla [11]. El tipo de investigación realizada fue cuantitativo, con un diseño experimental de 
bloques completos al azar, con cinco modalidades de tratamiento según el producto de control utilizado, aplicados en dos dosis, con tres repeticiones y cada repetición con diez unidades.

En esta investigación se aplicaron cinco productos comerciales con el fin de determinar su efectividad en Phyllophaga sp.: Mycotrol® 11 EW (Beauveria bassiana), BotaniGard® 50 WP (Beauveria Bassiana), Agro Gold® (Nueve cepas de Bacillus), B-Green $®$, entomonemátodo (Heterorhabditis bacteriophora) y Clorpiriphos ${ }^{\circledR}$ (insecticida químico como testigo comercial).

Los tratamientos utilizados se detallan en el cuadro 1.

Cuadro 1. Tratamientos utilizados para determinar el efecto de cuatro productos biológicos en el combate de Phyllophaga sp.

\begin{tabular}{|c|c|}
\hline Tratamiento & Descripción de los tratamientos \\
\hline T1 & Mycotrol $\mathbb{R} 11$ EW (Beauveria bassiana, cepa GHA) \\
\hline $\mathrm{T} 2$ & Botani Gard® 50 WP (Beauveria bassiana, cepa GHA) \\
\hline T3 & Agro Gold $\AA$ (nueve cepas de Bacillus spp) \\
\hline T4 & B-Green $®$ (entomonemátodo Heterorhabditis bacteriophora) \\
\hline T5 & Producto químico \\
\hline
\end{tabular}

Para la realización del proyecto se desarrollaron las fases que se detallan a continuación:

\section{Fase 1: Preparación inicial}

Se utilizaron tres casas malla de cuatro metros cuadrados y de tres metros de alto cada una (anexo 1). Dentro de cada casa malla se colocó sarán en el piso y sobre este las bolsas con el sustrato, elaborado con una mezcla de tierra y granza de arroz y esterilizado con vapor.

En cada ambiente controlado se colocaron cien bolsas con plantas de maíz como cultivo soporte, para que las larvas de joboto pudieran tener condiciones para mantener sus actividades. En total se prepararon trescientas bolsas. Una vez colocadas las bolsas en cada casa malla, se organizaron en grupos de 10 y cada grupo (10 en total) se enumeró de manera secuencial del 1 al 10 en la primera casa, del 11 al 20 en la segunda y del 21 al 30 en la tercera (figura 1).

\section{Fase 2: Diseño del experimento}

El diseño del experimento fue $2^{k}$, con $k$ igual a dos factores (Dosis y Aplicación). Cada tratamiento se aplicó respondiendo a una dosis preestablecida, de tal manera que en los tres ambientes controlados se evaluó la respuesta al producto. En el cuadro 2 se presentan los tratamientos y las dosis utilizadas.

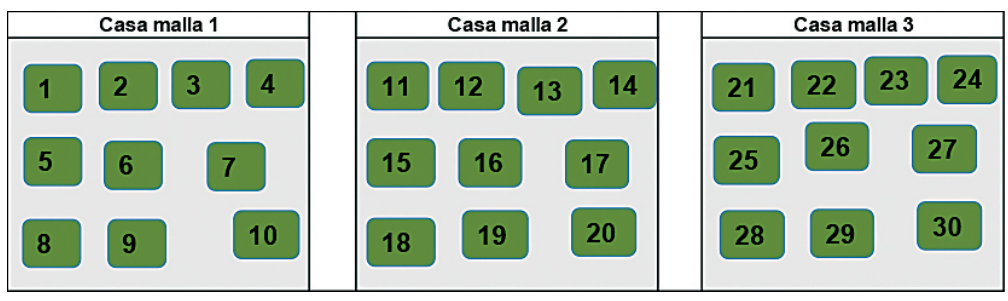

Figura 1. Distribución de las unidades experimentales, para determinar el efecto de cuatro productos biológicos en el combate de Phyllophaga sp. 
Cuadro 2. Descripción de los tratamientos y dosis utilizadas para determinar el efecto de cuatro productos biológicos en el combate de Phyllophaga sp.

\begin{tabular}{|c|c|c|c|}
\hline Tratamiento & Producto & Dosis 1 & Dosis 2 \\
\hline 1 & Mycotrol $@ 11 \mathrm{EW}$ & $1,5 \mathrm{cc} /$ litro & $2,25 \mathrm{cc} /$ litro \\
\hline 2 & Botani Gard® 50 WP & $1 \mathrm{gr} /$ /itro & $1,5 \mathrm{gr} / \mathrm{litro}$ \\
\hline 3 & Agro Gold $®$ & $5 \mathrm{cc} /$ litro & $7,5 \mathrm{cc} / \mathrm{litro}$ \\
\hline 4 & B-Green $®$ & $300000 / \mathrm{m}^{2}$ & $450000 / \mathrm{m}^{2}$ \\
\hline 5 & Producto químico & $1 \mathrm{cc} /$ litro & 1,5 cc/litro \\
\hline
\end{tabular}

Una vez establecidos los tratamientos, se procedió a definir la distribución de las dosis en cada casa malla (cuadro 3).

Cuadro 3. Distribución de tratamientos según dosis en cada unidad experimental, para determinar el efecto de cuatro productos biológicos en el combate de Phyllophaga sp.

\begin{tabular}{|c|c|c|}
\hline Tratamiento & Dosis 1 & Dosis 2 \\
\hline 1 & $1-11-21$ & $6-16-26$ \\
\hline 2 & $2-12-22$ & $7-17-27$ \\
\hline 3 & $3-13-23$ & $8-18-28$ \\
\hline 4 & $4-14-24$ & $9-19-29$ \\
\hline 5 & $5-15-25$ & $10-20-30$ \\
\hline
\end{tabular}

\section{Fase 3: Colocación de larvas}

Las larvas de Phyllophaga sp. fueron recolectadas en un cultivo de caña del Ingenio El Palmar, ubicado en Miramar de Puntarenas. Las larvas se transportaron en bandejas para evitar el canibalismo entre ellas. En la semana treinta y tres se colocaron tres larvas de Phyllophaga sp. por cada bolsa, para un total de novecientas larvas utilizadas.

\section{Fase 4: Aplicación de productos}

En la semana treinta y siete se realizó la primera aplicación de los cinco productos seleccionados para el ensayo. En la semana treinta y ocho se realizó la segunda aplicación de los cinco productos.

\section{Fase 5: Monitoreo}

Durante el ensayo se efectuaron tres monitoreos. El primero se realizó diez días después de la primera aplicación de los tratamientos y tres días después de la segunda aplicación. En esa ocasión se evaluaron tres bolsas de cada unidad experimental por cada dosis utilizada.

El segundo se hizo un mes después de la primera aplicación y tres semanas después de la segunda aplicación; al igual que en el primer monitoreo, se evaluaron tres bolsas de cada unidad experimental por cada dosis utilizada. El tercer monitoreo se realizó cinco semanas después de la primera aplicación y cuatro semanas después de la segunda aplicación; se evaluaron cuatro bolsas de cada unidad experimental por cada dosis utilizada. En todos los monitoreos las bolsas fueron abiertas para extraer por completo el sustrato y revisar con detalle la condición de las larvas de joboto. 


\section{Fase 6: Evaluación de las larvas afectadas}

Las larvas de Phyllophaga sp. obtenidas en el monitoreo fueron llevadas al Laboratorio de Diagnóstico y Evaluación de la empresa Bio Control, S.A., para determinar el efecto por los productos utilizados.

\section{Fase 7: Evaluación de resultados.}

El diseño del experimento fue 2k, con k igual a dos factores (Dosis y Aplicación). Los datos obtenidos se tabularon y se les realizó un análisis de varianza (andeva).

\section{Resultados y discusión}

Según los resultados obtenidos del análisis estadístico, tres de los cuatro productos microbiológicos presentaron efectos para el control de Phyllophaga sp. El producto de mejor resultado fue el Mycotrol $尺 11 \mathrm{EW}$, con ingrediente activo Beauveria bassiana, cepa GHA, hongo entomopatógeno que mostró alta capacidad patogénica. Los otros dos que produjeron resultados significativos fueron Agro Gold®, formulado a base de nueve cepas de Bacillus, y el entomonemátodo Heterorhabditis bacteriophora, con nombre comercial B - Green®.

En el cuadro 4 se muestra el resumen de los resultados obtenidos al aplicar un andeva a los datos generados por el experimento; estos datos se clasificaron por tratamiento y la condición de las larvas de Phyllophaga sp., vivas y muertas.

Cuadro 4. Valores de probabilidad según las diferentes pruebas aplicadas a los datos procedentes de cada tratamiento y según la condición de las larvas de Phyllophaga sp.

\begin{tabular}{|c|c|c|c|c|c|c|}
\hline \multicolumn{7}{|c|}{ Valores de probabilidad ( $p)$} \\
\hline \multirow[b]{2}{*}{ Tratamiento } & \multirow{2}{*}{$\begin{array}{l}\text { Condición de } \\
\text { larvas }\end{array}$} & \multirow[b]{2}{*}{ Homocedasticidad (1) } & \multirow{2}{*}{$\begin{array}{l}\text { Normalidad de } \\
\text { residuos }\end{array}$} & \multicolumn{3}{|c|}{ Prueba GLM (4) } \\
\hline & & & & Dosis & Aplicación & $\begin{array}{c}\text { Dosis y } \\
\text { aplicación }\end{array}$ \\
\hline \multirow{2}{*}{ T1 } & Vivas & 0,426 & $<0,01 \quad$ (2) & 0,629 & 0,002 & 0,629 \\
\hline & Muertas & 0,919 & $<0,01 \quad$ (2) & 0,027 & 0,123 & 0,231 \\
\hline \multirow{2}{*}{ T2 } & Vivas & 0,732 & $>0,1 \quad(3)$ & 0,258 & 0,000 & 0,258 \\
\hline & Muertas & 0,766 & $<0,01 \quad$ (2) & 0,573 & 0,094 & 0,311 \\
\hline \multirow{2}{*}{ T3 } & Vivas & 0,823 & $<0,01 \quad$ (2) & 0,544 & 0,135 & 0,873 \\
\hline & Muertas & 0,658 & $<0,01 \quad$ (2) & 0,113 & 0,004 & 0,264 \\
\hline \multirow{2}{*}{ T4 } & Vivas & 0,455 & $<0,046$ & 0,659 & 0,006 & 0,973 \\
\hline & Muertas & 0,414 & $<0,01 \quad(2)$ & 0,807 & 0,014 & 0,812 \\
\hline \multirow{2}{*}{ T5 } & Vivas & 0,070 & $<0,01 \quad$ (2) & 1,00 & 0,000 & 1,00 \\
\hline & Muertas & 0,898 & $<0,01$ & 0,260 & 0,277 & 0,758 \\
\hline
\end{tabular}

(1) Se utiliza la prueba de Levene para encontrar estos valores de homocedasticidad.

(2) Prueba de normalidad de residuos de Kolmogorov - Smirnov.

(3) Prueba de normalidad de residuos de Ryan - Joiner.

(4) Se realiza un análisis de varianza aplicando la prueba GLM con distribución F - Snedecor.

Todas las pruebas se realizaron con un $\alpha=0,05$ 
En el cuadro 4 se analizó los factores dosis, aplicación y dosis x aplicación tanto para la condición de larvas vivas como de larvas muertas en cada uno de los tratamientos realizados. Para fines del estudio solo se consideraron los valores de $p<0,05$ obtenidos en la condición de larva muerta en cada tratamiento y según cada factor analizado. Se determinó para T1 (Mycotro|ß 11 EW) y para la condición de larvas muertas el factor dosis tuvo significancia estadística, con un valor de $p=0,027$ y solo en este tratamiento el factor dosis fue significativo. Para el caso de T3 (Agro Gold®) para la condición de larvas muertas el factor aplicación fue significativo, con un valor de $p=0,004$, y para T4 (B-Green $®$ ), en la condición de larvas muertas el factor aplicación fue también estadísticamente significativo, con un valor de $p=0,014$. Para los tratamientos T2 y T5, el valor de $p$ en la condición de larvas muertas en los tres factores fue $>0,05$. También es importante mencionar que la interacción dosis x aplicación no tuvo significancia estadística en ninguno de los tratamientos y en ninguna de las condiciones de las larvas.

\section{Tratamiento 1 (T1): Mycotrol® $11 \mathrm{EW}$}

Al analizar los resultados del cuadro 1, se determinó que Mycotrol@ 11EW es el producto más eficiente, ya que causa la mayor mortalidad de larvas de Phyllophaga sp.. Este producto está formado por el hongo entomopatógeno Beauveria bassiana, cepa GHA. Este hongo se puede encontrar de forma natural en el suelo y causa la muerte de varios órdenes de insectos, por lo que se ha utilizado como biocontrolador contra coleópteros, dípteros, heterópteros, homópteros, lepidópteros, tisanópteros y ácaros tetraníquidos [15], [16].

Este hongo tiene un ciclo de vida que se compone de dos fases, una patogénica y otra saprofítica. El proceso de desarrollo de Beauveria bassiana se divide en varias etapas. Se inicia con la adhesión, que es el primer contacto del hongo con el insecto y se da cuando la espora (conidio) se deposita en la superficie del insecto objetivo a través de la aplicación foliar o drench. Luego de la adhesión se da la germinación, etapa en la que el conidio comienza a desarrollar el tubo germinativo, el cual mediante una estructura llamada apresorio se sujeta y de esta manera se fija a la superficie del insecto. Con una humedad relativa de 92 por ciento y temperaturas en un rango de 23 a 25 grados centígrados, una espora puede germinar de manera exitosa. Luego de que la espora se ha adherido y ha germinado (mecanismos físicos), se inicia la etapa de penetración por medio de mecanismos químicos producidos por la acción de enzimas, principalmente proteasas, lipasas y quitinasas. La acción de estas enzimas en la superficie del insecto es hidrolítica y su función principal es la de degradar el tejido en el área por donde el hongo penetra al insecto, facilitando así su entrada [12].

Cuando B. bassiana ingresa al hospedero desarrolla estructuras que le permiten colonizarlo; una vez dentro produce toxinas, entre las que destaca la beauvericina, la cual favorece la ruptura del sistema inmunológico del insecto, facilitando su entrada en todos sus tejidos. Posteriormente se presenta la muerte de la plaga. Una vez muerto el insecto, el hongo multiplica las hifas (unidades infectivas), las cuales crecen al invadir por completo todo el hospedero. Si las condiciones de humedad relativa y temperatura lo favorecen, el hongo puede crecer sobre el insecto mostrando estructuras de color blanco; si no es así, el insecto muerto mantiene apariencia de momia [12].

Como resultado, la dosis fue significativa, con un valor de $p=0,027$; se determinaron los datos estadisticodescriptivos para larvas muertas, que se muestran en el cuadro 5. 
Cuadro 5. Valores en porcentaje y desviación estándar de los datos de larvas muertas, con la prueba GLM, en la interacción de los factores dosis y aplicación, para el producto Mycotrol@ 11EW

\begin{tabular}{|c|c|c|}
\hline Tratamiento ( T 1) & Media (porcentaje de larvas muertas) & Desviación estándar \\
\hline Dosis 1 - Aplicación 1 & 11,00 & 16,50 \\
\hline Dosis 1 - Aplicación 2 & 31,43 & 26,56 \\
\hline Dosis 2 - Aplicación 1 & 36,70 & 30,60 \\
\hline Dosis 2 - Aplicación 2 & 39,29 & 26,85 \\
\hline
\end{tabular}

En el cuadro 5 se observa que la dosis 2 del tratamiento 1, (2,25 cc/litro), en la segunda aplicación, fue la que causó una mayor mortalidad de larvas. Las dos aplicaciones son importantes debido a que en la primera, el microorganismo tiene que establecerse. Esto implica que el hongo necesita adaptarse a las nuevas condiciones de suelo, humedad, temperatura y radiación. Además, el hongo debe establecerse y multiplicarse para poder actuar como un agente biocontrolador, por lo que de no realizarse un análisis microbiológico para conocer cantidad de esporas presentes por gramo de suelo, lo más recomendable es realizar la segunda aplicación del producto, para asegurar la cantidad de esporas que pueden controlar la plaga.. Por lo que la segunda aplicación viene a reforzar y a incrementar la cantidad de esporas que pueden controlar a la plaga.

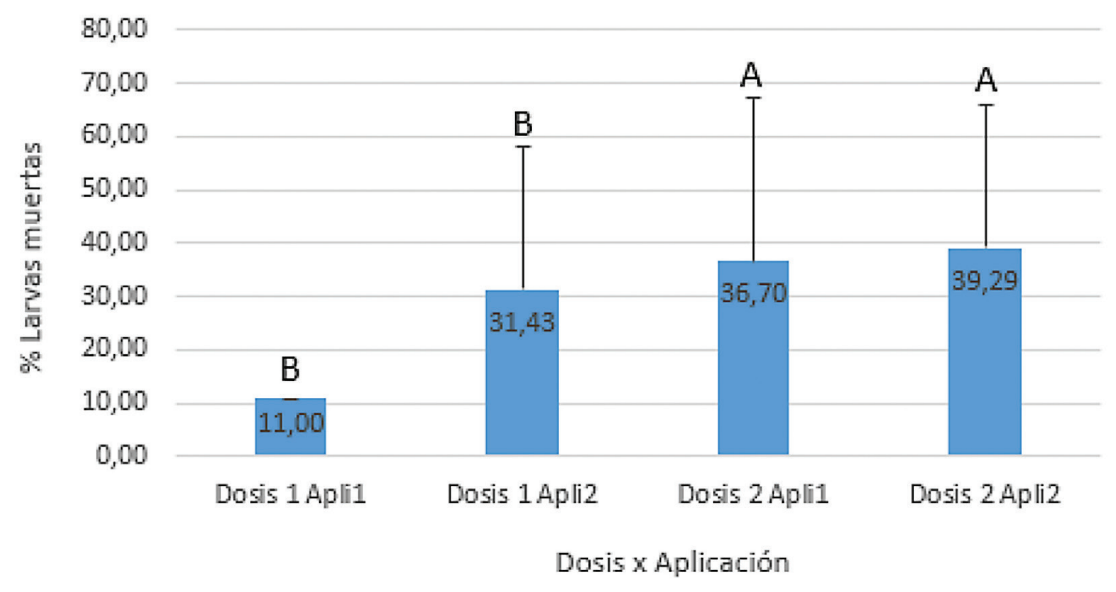

Figura 2. Gráfico del análisis del porcentaje de larvas muertas según la prueba GLM, con la interacción de los factores dosis y aplicación

Al analizar la figura 2, se determinó que la dosis 2 de T1, (2,25 cc / litro) tuvo efecto sobre las larvas de Phyllophaga sp. Con la aplicación 1 se obtuvo un 36,70 \% de larvas muertas y con la 2 , un 39,29 \% de larvas muertas. Aunque la diferencia en cuanto al porcentaje de control entre la primera aplicación y la segunda no fue muy grande, se puede considerar que el incremento en la cantidad de microorganismos en la microbiota del suelo es importante para un mejor control de Phyllophaga sp., por lo que se esperaría que al incrementar las aplicaciones de microorganismos, el control de la plaga sea más eficiente.

El resultado obtenido es consecuente con estudios realizados donde se ha demostrado que $B$. bassiana es un hongo entomopatógeno efectivo para control de plagas [13]. Es importante 
considerar que no todas las cepas de hongos entomopatógenos, aunque se hable de un mismo género, tienen la misma virulencia contra una misma plaga [14]. Para el caso de Mycotrol@11 EW, es claro que la cepa de B. bassiana GHA sí es virulenta contra larvas de Phyllophaga sp., ya que fue el producto con el que se obtuvo el mejor resultado.

Pese a esa virulencia, las larvas de Phyllophaga sp., al desarrollarse en medios en los que de manera constante están en contacto con una gran diversidad de microorganismos, entre los que se incluyen los hongos entomopatógenos, progresivamente han ido adquiriendo resistencia contra la mayoría de ellos, por lo que que cada vez es más difícil encontrar cepas con alta capacidad patogénica.

Mycotrol® $11 \mathrm{EW}$ es un producto de amplio espectro para control de plagas, donde se incluye a los coleópteros. Este producto fue desarrollado por la empresa Mycotech Corp, ubicada en Butte, Montana, USA, la cual utiliza tecnología de avanzada en su biofabricación [17]. La formulación de Mycotrol® 11 EW está basada en tecnología de formulación coloidal, la cual crea una emulsión de transporte coloidal (ETC) que protege los conidios del hongo contra condiciones adversas de clima, como también contra los rayos ultravioleta, lo que permite que la aplicación sea efectiva sin importar el momento del día en que se realice. La ETC también mejora la penetración y la adherencia del producto. La carga iónica que tiene la ETC mueve las conidias de B.bassiana al sitio de acción y las adhiere a la cutícula del insecto [18].

\section{Tratamiento 3 (T3): Agro Gold®}

Como se observa en el cuadro 4, para T3, en la condición de larvas muertas la aplicación fue significativa según la prueba GLM, ya que produjo un valor de $p=0,004$. Con este resultado se determinaron los datos estadisticodescriptivos para larvas muertas (anexo 2, figura 8).

Al haber diferencia significativa para el factor aplicación en T3, se procedió a realizar una comparación entre los factores dosis y aplicación con la prueba de Tukey, y se determinó que los porcentajes más altos de larvas muertas se obtuvieron con la aplicación 2, sin importar la dosis utilizada, tal como se observa en el cuadro 6.

Cuadro 6. Valores promedio en porcentaje y desviación estándar de los datos de larvas muertas con la prueba GLM, en la interacción de los factores dosis y aplicación para el producto Agro Gold $\circledast$

\begin{tabular}{|c|c|c|}
\hline Tratamiento (T3) & Media (porcentaje de larvas muertas) & Desviación estándar \\
\hline Dosis 1 - Aplicación 1 & 3,67 & 11,00 \\
\hline Dosis 1 - Aplicación 2 & 31,43 & 22,08 \\
\hline Dosis 2 - Aplicación 1 & 22,00 & 23,33 \\
\hline Dosis 2 - Aplicación 2 & 34,67 & 28,76 \\
\hline
\end{tabular}

Los valores obtenidos, porcentaje de larvas muertas y desviación estándar, se graficaron y tomando el resultado de la prueba de Tukey, se determinó que la aplicación 2 de Agro Gold fue la que tuvo mejor efecto sobre las larvas de Phyllophaga sp. 


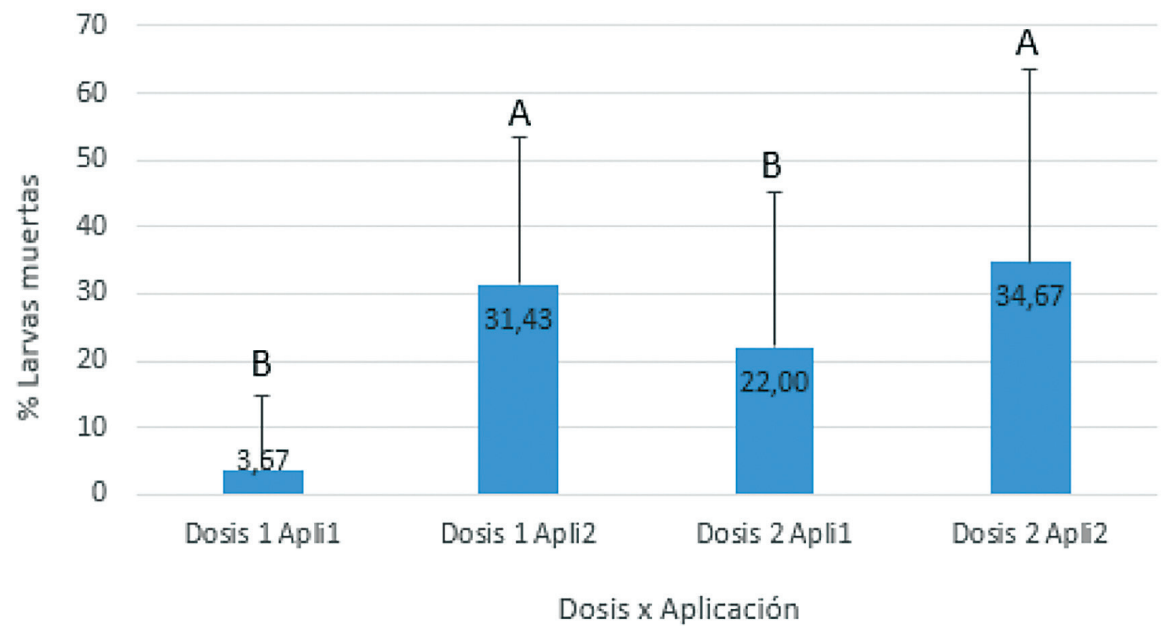

Figura 3. Grafico del análisis de porcentaje de larvas muertas según la prueba GLM, con la interacción de los factores dosis y aplicación, para el producto Agro Gold®

Agro Gold® es un producto biológico conformado por nueve cepas de Bacillus sp., una de las cuales es B. popilliae; el componente activo B. popilliae es grampositivo. Es la bacteria que más éxito ha tenido contra larvas de escarabajos, entre las que se incluye la Phyllophaga sp. B. Papilliae es un parásito obligado cuyas esporas son muy resistentes a las condiciones adversas que se le pueden presentar en el ambiente, lo que permite que se pueda formular industrialmente y mantener sus características como agente de control biológico. Las larvas de Phyllophaga sp. adquieren esta bacteria cuando se alimentan de materiales contaminados con las esporas y estas ingresan al tracto digestivo.Las esporas de B. popilliae germinan en el intestino de la larva y las proteínas de cristal paraesporal se liberan y activan, dañando la pared intestinal de este insecto, lo que les permite ingresar fácilmente a la hemolinfa y producirle la muerte [19].

Como cualquier microorganismo, B. popilliae necesita de una dosis alta de establecimiento o colonización, para después poder competir con otros por alimento y espacio, como sucede una vez establecido en el suelo, donde competirá con las plagas. La muerte de la larva de Phyllophaga sp. es resultado de la acción del esporangio (estructura del Bacillus), que está formado por dos partes, la espora y el cristal proteico paraespora, que al germinar en la hemolinfa produce en las larvas una infección conocida como enfermedad lechosa, la cual lesprovoca la muerte [19].

\section{Tratamiento 4 (T4): B - Green®}

Como se observa en el cuadro 4, para T4, en la condición de larvas muertas la aplicación fue significativa según la prueba GLM, ya que se obtuvo un valor de $p=0,014$. Con este resultado se determinaron los datos estadisticodescriptivos, para las larvas muertas.

Al haber diferencia significativa para el factor aplicación en T4, se procedió a realizar una comparación entre los factores dosis y aplicación con la prueba de Tukey, y se determinó que los porcentajes más altos de larvas muertas se obtuvieron con la aplicación 2, sin importar la dosis utilizada, tal como se observa en el cuadro 7.

Los valores obtenidos, el porcentaje de larvas muertas y la desviación estándar, se graficaron y tomando el resultado de la prueba de Tukey, se determinó que la aplicación dos (segunda aplicación) de B - Green® fue la que tuvo mejor efecto sobre las larvas de Phyllophaga sp. 
Cuadro 7 . Valores en porcentaje y desviación estándar de los datos de larvas muertas con la prueba GLM, en la interacción de factores dosis y aplicación, para el producto B-Green®

\begin{tabular}{|c|c|c|}
\hline Tratamiento (T4) & Media (porcentaje larvas muertas) & Desviación estándar \\
\hline Dosis 1 - Aplicación 1 & 7,33 & 14,55 \\
\hline Dosis 1 - Aplicación 2 & 28,33 & 28,29 \\
\hline Dosis 2 - Aplicación 1 & 11,00 & 16,5 \\
\hline Dosis 2 - Aplicación 2 & 28,38 & 32,02 \\
\hline
\end{tabular}

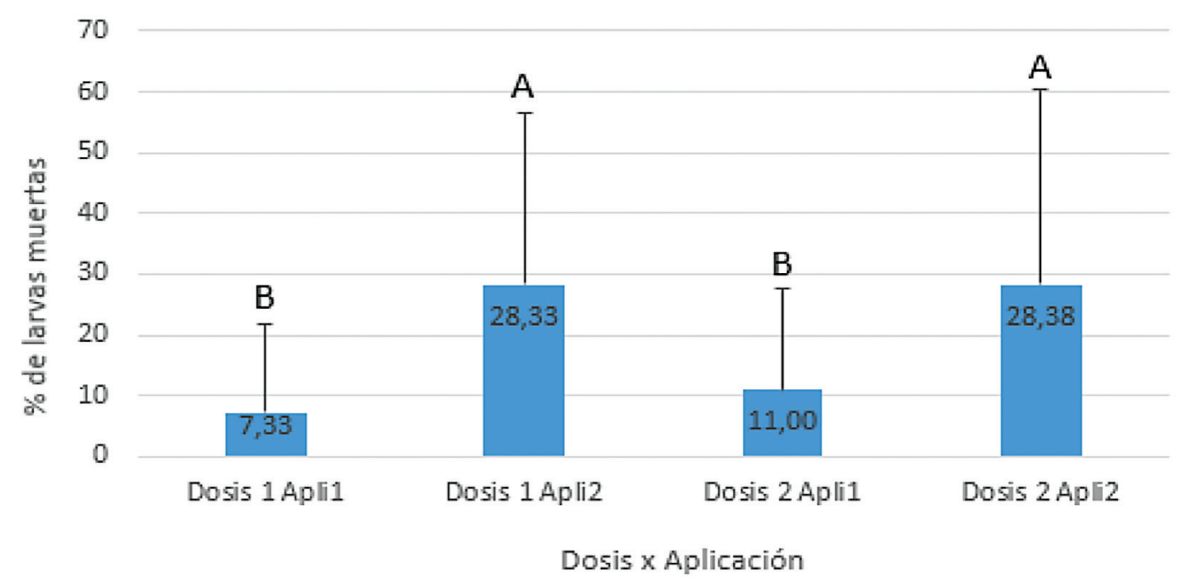

Figura 4. Gráfico del análisis del porcentaje de larvas muertas según la prueba GLM, con la interacción de los factores dosis y aplicación, para el producto B - Green®

Al analizar la figura 4 se determinó que T4, que corresponde al producto B- Green®, cuyo ingrediente activo es el entomonemátodo Heterorhabditis bacteriophora y que está reportado como un agente de control de coleópteros, logró ejercer control sobre el 28,38 por ciento de las larvas de Phyllophaga sp. que fueron tratadas. Con las dos aplicaciones que se realizaron del biocontrolador, espaciadas una semana, se logró obtener mejor resultado. Se pudo observar que las dosis no fueron significativas, así que se puede utilizar cualquiera de las dos evaluadas. $H$. bacteriophora vive de manera simbiótica con la bacteria Photorhabdus luminescens; el nemátodo transporta la bacteria, que al llegar al hemocele de la larva causa la muerte del hospedero; el estado juvenil 3 de los nemátodos es el que adopta la bacteria para poder actuar sobre nuevos hospederos [20]. La acción de los entomonemátodos se da por la penetración de estos al insecto hospedante. El juvenil que ingresa al insecto lo hace a través de las aberturas naturales ano, boca y espiráculos, o también por puntos o zonas donde la cutícula es muy delgada[21].

La bacteria $P$. luminescens una vez que ha ocasionado la muerte de la larva se encarga de producir antibióticos para evitar que otros microorganismos la invadan; además descompone por completo los tejidos de las larvas, para convertirlas en fuente de alimento para los nemátodos. Los nemátodos se reproducen dentro del cadáver y los juveniles J3, que son los infectivos, migran en busca de nuevas presas [16]. El porcentaje de efectividad de B- Green® fue bajo, lo que se pudo deber a diferentes variables que inciden en la acción del entomonemátodo H.bacteriophora, que es el ingrediente activo. 
Al considerar todas las posibles vías de ingreso del nematodo, se determinó que entre las variables que afectan la acción del producto sobre la plaga están el acondicionamiento natural de las larvas para repeler la acción de los entomonemátodos, la obstrucción de la boca del hospedero por materia orgánica, el exceso de excretas y espiráculos muy estrechos [22]; también la temperatura elevada y una alta radiación solar pueden tener efecto sobre su efectividad [23].

La utilización de los nemátodos entomopatógenos como B-Green® presenta ventajas tales como su fácil aplicación, su disponibilidad comercial, su preparación en agua y su aplicación vía sistema de riego o en drench [24]. Los entomonemátodos son inocuos para el ser humano; tras una aplicación masiva y a falta del huésped, permanecen en poblaciones operativas durante meses. En presencia del hospedero se reproducen aumentando sus poblaciones y como son muy específicos en su preferencia por ciertos hospederos, permiten evitar daños secundarios [21].

\section{Conclusiones}

De los cinco productos evaluados en este ensayo (cuatro biológicos y uno químico), cuyo análisis se enfocó en la condición de larvas muertas de Phyllophaga sp., solo tres de los cuatro biológicos tuvieron efecto en el combate de las larvas. Estos productos fueron los

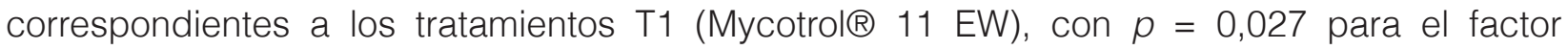
dosis; T3 (Agro Gold $®$ ), con $p=0,004$, y T4 (B-Green $尺$ ), con $p=0,014$, ambos para el factor aplicación. No se encontró evidencia significativa para los tratamientos T2 (BotaniGard®) y T5 (producto químico) en ninguno de los factores evaluados (dosis, aplicación, dosis x aplicación).

El factor de análisis dosis tuvo significancia estadística, con $p=0,027$, con el producto Mycotrol@ $11 \mathrm{EW}, \mathrm{T1}$, que además fue el tratamiento que mejor resultado dio con la dosis dos $(2,25 \mathrm{cc} /$ litro). En la primera aplicación se obtuvo un 36,70 \% de efectividad y un 39,29 \% de efectividad en la segunda aplicación. Este incremento se puede atribuir a un aspecto acumulativo del biocontrolador en el sustrato, por lo que se sugiere realizar aplicaciones periódicas del producto para incrementar su población de esporas en el suelo y así mejorar su eficiencia en el combate de la plaga.

El factor de análisis aplicación tuvo significancia estadística para los tratamientos T3 (Agro Gold $(\mathrm{B})$, con $p=0,004$, y T4 (B - Green $($ ) $)$, con $p=0,014$. De los dos productos se requirieron dos aplicaciones con una frecuencia semanal para obtener resultado positivo. En el caso del producto Agro Gold $\AA$, puesto que se necesitan dos aplicaciones como mínimo y al no haber diferencia significativa entre las dos dosis, se recomienda usar $5 \mathrm{cc} / \mathrm{L}$. En el caso del producto B- Green, se puede aplicar a una dosis de 300000 nemátodos $/ \mathrm{m}^{2}$.

Los tres productos evaluados satisfactoriamente para el combate de Phyllophaga sp. presentaron porcentajes de control que prueban que pueden ser utilizados en programas de manejo de la plaga. Hay que considerar que estas herramientas deben ser utilizadas bajo criterios técnicos de aplicación siguiendo las recomendaciones apropiadas para el uso de cada una de ellas y teniendo siempre en cuenta que los productos microbiológicos tendrán un mejor impacto desde el punto de vista de control cuando sean utilizados de manera preventiva, o sea iniciando su implementación cuando los niveles de incidencia de la plaga son bajos y esto según el criterio de cada técnico o productor o el umbral económico de cada cultivo. 


\section{Recomendaciones}

Los productos, Mycotrol $\circledast$ 11EW, Agro Gold® y B - Green $®$ se pueden utilizar dentro de un programa MIPE para el combate de Phyllophaga sp., ya que se verificó que actúan en el combate de las larvas de esta plaga Estos productos son una opción en la lucha contra Phyllophaga sp., ya que no tienen impacto negativo para el ambiente ni para los usuarios y permiten que la microflora y la fauna del suelo puedan mantenerse en equilibrio ecológico, mediante un manejo más racional de los recursos.

Es muy importante implementar programas de monitoreo continuo de la plaga para identificar el momento en que están presentes las larvas de Phyllophaga sp., y así poder definir cuándo aplicar alguno de los productos (Mycotrol® 11EW, Agro Gold®, B - Green $\AA$ ), o bien la combinación de ellos, de manera que se pueda lograr que el biocontrolador encuentre las mejores condiciones para realizar su acción sobre el hospedero.

Por ser Mycotrol $\AA_{11 \mathrm{EW}}$, Agro Gold $₫$ y B - Green $\AA$ productos biológicos, se debe considerar como un requisito importante que su aplicación sea en suelos o sustratos húmedos, ya que la humedad permitirá un desarrollo adecuado de estos organismos, y para el caso particular de B - Green® es fundamental evitar las temperaturas elevadas y la radiación solar alta en el momento de aplicarlo, ya que los entomonemátodos son sensibles a estas variables; lo mejor es aplicar este producto muy temprano en la mañana o bien al atardecer.

\section{Referencias}

[1] J. Calvo, J. Vargas, M. Araya. "Control químico de Phyllophaga en caña de azúcar (Saccharum officinarum)". Obtenido de https://www.atamexico.com.mx/wp-content/uploads/2017/11/5-PLAGAS-2016.pdf.

[2] A.B.S. King, "Biología, identificación y distribución de especies económicas de Phyllophaga en América Central", en Biología y Control de Phyllophaga sp. [Memoria], P.J. Shannon y M. Carballo, eds. CATIE, Costa Rica: 1996, pp. $50-61$.

[3] M. G. Klein y H. Kaya, "Bacillus and Serratia species for scarab control", en Memórias do Instituto Oswaldo Cruz 90 (1), 87-95, 1996.

[4] G. Abarca y M. Quesada. "Especies del complejo de jobotos (Phyllophaga sp., Anomala spp. y Cyclocephala spp.) asociadas a cultivos, en el Valle Central y Pacífico seco de Costa Rica", Agronomía Mesoamericana 8 (2), 44-53, 1997.

[5] T. Cueva M. M., Identificación taxonómica de las especies de Phyllophaga (Col. Scarabaeidae) presentes en diez cultivos de importancia económica en la Provincia de Los Ríos, tesis de ingeniería, Universidad de las Fuerzas Armadas, Departamento de Ciencias de la Vida y la Agricultura, Carrera de Ingeniería Agropecuaria, Quito, Ecuador, 2014.

[6] M.H. Badii y J.L. Breu, "Control biológico, una forma sustentable de control de plagas" (Biological control, a sustainable way of pest control), Daena: International Journal of Good Conscience 1 (1), 82-89, 2006.

[7] J. Lorea-Gallardo, J.F. Pérez-Dominguez y L.A. Rodríguez-Del Bosque, "Control químico". Obtenido de http://recursosbiblio.url.edu.gt/publicjlg/biblio_sin_paredes/fac_agri/2015/plag_su/cap/11.pd. [recuperado en 2015].

[8] R.H. González y P.S. Rojas. Estudio analítico del control biológico de plagas agrícolas en Chile. Santiago: Ed. Universitaria, 1967.

[9] Maranhão De Albuquerque, Elizabeth Araujo y Eduardo Henrique, "Hongos entomopatógenos: importante herramienta para el control de "moscas blancas"(Homoptera: Aleyrodidae)", en Anais da Academia Pernambucana de Ciência Agronômica 5, 2013, 209-242.

[10] M.P. Quintero, Comparación en laboratorio de la patogenicidad de tres especies de nemátodos entomopatógenos (Rhabditida) sobre larvas de tercer instar de Phyllophaga menetriesi (Blanchard)(Coleoptera: Scarabaeidae). tesis en biología, Universidad del Valle, Colombia, 2003.

[11] C.M. Alvarado, F.A. Díaz y M.R. Hernández, "Tecnología para producir tomate en casa malla para el norte de Tamaulipas”, INIFAP, Folleto para productores, no. MX-0-310301-49-03-13-10-60, ISBN: 978-607-37-0330-7, 2014. 
[12] G. M. García, G. S. Cappello, G. J. Lesher y M. R. Martínez, "Hongos entomopatógenos como una alternativa en el control biológico", Kuxulkab 15 (27),25-28, 2015

[13] A. Téllez-Jurado, M. G. Cruz Ramírez, Y. Mercado Flores, A. Asaff Torres y A. Arana-Cuenca, "Mecanismos de acción y respuesta en la relación de hongos entomopatógenos e insectos", Revista Mexicana de Micología, 30, 73-80, 2009

[14] E. Nava-Pérez, C. García-Gutiérrez, J. R. Camacho-Báez y E. L. Vázquez-Montoya, "Bioplaguicidas: una opción para el control biológico de plagas", Ra Ximhai, 8 (3), 17-29. 2012.

[15] E. Hidalgo, "Uso de microorganismos para el control de Phyllophaga sp", Manejo Integrado de Plagas (Cost a Rica), 60, i - i v, 2001.

[16] A. Santamaría, J. Costa-Comelles, A. Alonso, J. M. Rodríguez y J. Ferrer, "Ensayo del hongo entomopatógeno Beauveria bassiana (Balsamo) Vuillemin para el control de la mosca blanca de los cítricos Aleurothrixus floccosus (Maskell)(Homoptera: Aleyrodidae) y su acción sobre el parásito Cales noacki (Howard)(Hymenoptera: Aphelinidae)", Bol. San. Veg. Plagas, 24 (6), 695-706.

[17] D. Rodríguez, M. Torres, L. Uribe y L. Flores. "Susceptibilidad de los estadios L2 y L3 de Phyllophaga elenans a una cepa nativa de Heterorhabditis sp. en condiciones de invernadero", Agronomía Costarricense, 33 (2), 171-182, 2009.

[18] J. L. Navas R. Eficacia de Beauveria bassiana (Balsamo) vuillemin 1912 como controlador biológico de Cosmopolites sordidus Germar 1824 (Coleoptera: Dryophthoridae) en una plantación de banano en la región Caribe de Costa Rica, tesis de licenciatura, Universidad Nacional, Costa Rica, 2011.

[19] S. P. Wraight and M. E. Ramos, "Application parameters affecting field efficacy of Beauveria bassiana foliar treatments against Colorado potato beetle Leptinotarsa decemlineata", Biological Control, 23 (2), 164-178, 2002.

[20] Lam International. Ficha Técnica de Mycotrol. Obtenido de http://lamintl.com/products/bioinsecticides/mycotrol, 2013.

[21] J. Zhang, T. C. Hodgman, L. Krieger, W. Schnetter, and H. U. Schairer, "Cloning and analysis of the first cry gene from Bacillus popilliae," Journal of Bacteriology, 179 (13), 4336-4341, 1997.

[22] T. Ciche, "The biology and genome of Heterorhabditis bacteriophora". Obtenido de http://www.wormbook.org/ chapters/www_genomesHbacteriophora/genomesHbacteriophora.html, 2007.

[23] A. Sáenz, "Importancia de los nematodos entomopatógenos para el control biológico de plagas en palma de aceite", Revista Palmas, 26 (2), 41-57, 2005.

[24] S. Hazir, H. Kaya, P. Stock, and N. Keskin, "Entomopathogenic nematodes (Steinernematidae and Heterorhabditidae) for biological control of soil pests," Turkish Journal of Biology, 27 (4), 181-202, 2003. 